\title{
Enhancement of effective means and efficient the applicability of the manual: methods and practical alternative
}

\author{
Parnaz Imani1 $^{1}$; Sara Anaile Ribeiro da Silva ${ }^{1}$; Valdecy Ferreira Lima ${ }^{1}$
}

${ }^{1}$ UNINORTE-Laureate Internacional Universities. Rua Joaquim Nabuco, No 1615. Manaus/AM - Brasil. CEP: 69020-030.

Email: parnazimani@gmail.com, sara-anaile-adm@hotmail.com, lima.valdecy@ hotmail.com

\author{
Received: July $17^{\text {th }}, 2016$ \\ Accepted: September $20^{\text {th }}, 2016$ \\ Published: December, $22^{\text {th }}, 2016$ \\ Copyright (C2016 by authors and Institute \\ of Technology Galileo of Amazon (ITEGAM). \\ This work is licensed under the Creative \\ Commons Attribution International \\ License (CC BY 4.0). \\ http://creativecommons.org/licenses/by/4.0/ \\ cc) (i)(2) Open Acees:
}

\begin{abstract}
AABSTRACT
The application of the handbook is to clarify the vital importance of the correct use of the functions of a particular piece of equipment, handling and effective functioning. The use or non-availability when needed can cause serious problems to the equipment user or performing routines and processes in general, compromising quality management. The objective of this paper is to show the inefficiency or misuse of these, proposing alternative methods of improvement or innovation that makes effective use and effective applicability, thus contributing to ensuring after-sales quality. The methodology was exploratory and field research based on questionnaires, generating qualitative and quantitative data. The results confirmed that the making of these in standard format (paper), is not meeting designated goals when initially idealized and representing imminent danger, therefore, the relevance and the need to educate the public and managers, for their potential safety hazard and closes presenting ten suggestions for improvement or innovation as fruit (consequence) of the research.
\end{abstract}

Keywords: Manual, Handbook, Quality management, Standardization, E-manual, E-handbook.

\section{Aprimoramento de meios efetivos e eficientes da aplicabilidade dos manuais: métodos práticos e alternativos.}

\begin{abstract}
RESUMO
A aplicação dos manuais tem como vital importância o esclarecimento do uso correto das funções de um determinado equipamento, seu manuseio e funcionamento efetivo. $\mathrm{O}$ não uso ou a indisponibilidade quando necessário pode ocasionar graves problemas, ao equipamento, usuário ou na execução de rotinas e processos em geral, comprometendo a gestão de qualidade. O objetivo do artigo é mostrar a ineficiência ou desuso destes, propondo métodos alternativos de aprimoramento ou inovações que torne efetivo seu uso e eficaz sua aplicabilidade, contribuindo assim para a garantia de qualidade pós-venda. A metodologia adotada foi pesquisa exploratória e de campo baseada em aplicação de questionário, gerando dados qualitativos e quantitativos. Os resultados obtidos confirmaram que a confecção destes no formato padrão (papel), não vem atendendo os objetivos designados quando idealizados inicialmente e representando perigo iminente, portanto, a relevância e necessidade de conscientizar o público e gestores, quanto ao seu potencial risco de segurança e encerra-se apresentando dez sugestões de melhoria ou inovação como frutos (consequência) da pesquisa.
\end{abstract}

Palavras Chaves: Manual, Gestão de Qualidade, Padronização, E-manual, E-comunicação.

\section{INTRODUÇÃO}

Os manuais têm por função orientar, auxiliar e instruir tecnicamente aos usuários a respeito de dúvidas na utilização de um equipamento ou para realizar uma atividade, quando for um manual operacional. Conforme [1] manual é um texto didático, para ser utilizado por várias pessoas, que apresenta informações e orientações em linguagem técnica.

A utilização dos manuais pelas empresas até um determinado tempo não era obrigatória, após observar a necessidade tornou-se indispensável à utilização deste, seja 
produto ou serviço imprescindivelmente precisa ter o manual no intuito de ensinar ao usuário como usar o produto, quais suas funções, cuidados necessários para a manutenção do equipamento, possíveis perigos e muito mais. Hoje, é indispensável o estabelecimento de normas para que se garanta o padrão de qualidade aos diversos produtos e processos, contudo isso não sobrevinha em tempos remotos, onde as pessoas passaram muitas dificuldades por não ter um padrão adequado ao que estavam consumindo ou produzindo [2].

Segundo o [3] no seu Art. $8^{\circ}$ afirma que: é obrigado aos fornecedores, em qualquer hipótese, a dar as informações necessárias e adequadas a respeito do produto ou serviço oferecido. Tratando-se de produto industrial, ao fabricante compete prestar as informações a que se refere este artigo, através de impressos apropriados que devem acompanhar o produto. Desta forma, observa-se que existem normas e há uma necessidade de melhoria e aprimoramento para que assim gere uma boa aplicabilidade.

Acredita-se que há uma grande ineficiência quanto ao uso correto do manual para que se torne melhor é necessário que os criadores de manuais melhorem a comunicação utilizada nestes instrumentos, à comunicação para [4] é considerada na atualidade como algo imprescindível às empresas, merecendo cada vez mais, maior atenção. E por meio dela torna-se possível estabelecer canais que possibilitem o relacionamento ágil e transparente da direção da organização com o seu público interno e entre os próprios elementos que o integram.

\section{REVISÃO BIBLIOGRÁFICA}

\section{II.1. A COMUNICAÇÃO E O MANUAL}

A comunicação é uma ferramenta que permite a conexão entre profissionais, equipes, organizações, mercado e o ambiente interno e externo. Existe um tipo de comunicação que é fundamental para uma empresa, a comunicação escrita, de acordo com [1] para que ela seja eficaz, são necessárias: clareza e objetividade, precisão e persuasão para que assim possa obter a colaboração e a resposta esperadas.

Portanto, quando feita de forma clara e objetiva, a comunicação escrita torna-se essencial para o bom entendimento das várias atividades que uma organização pode exercer. Sendo transmitida através de: Cartas, Memorandos, Ofícios, Manuais, Relatórios, Ata, Procuração, etc.

A maioria dos manuais é: escritos, impressos e fazem parte da embalagem de um produto, no entanto o usuário final o despreza e começa a utilizar o produto, sem ao menos procurar ler a respeito das funções daquele produto.

Ao ocorrer problemas no funcionamento não sabem como proceder, pois não o leram e nem o encontram. Vale salientar que a maioria dos usuários reclama que não leem manuais porque não tem paciência, e que não conseguem entender, pois a linguagem é muito técnica e, dependendo do produto, não há muitas figuras ilustrando o passo a passo a ser seguido. Mas, observa-se que os manuais ajudam muito na compreensão de um procedimento e funções de um produto, basta ser feito de uma forma mais atraente e explicativa.

\section{II.2. A IMPORTÂNCIA DO MANUAL PARA O ELABORADOR E USUÁRIO}

O manual tem caráter informativo ou procedimental. Após a leitura o usuário tem um conhecimento mais amplo e claro sobre as informações relevantes e precisas referente a determinado produto, serviço, normas ou procedimentos a serem adotados.

O usuário cria o conhecimento a respeito das informações básicas, isto é, ao que se destina, qual a sua finalidade e proficuidade. Em seguida, tem acesso aos detalhes do conteúdo e por fim são apresentados os procedimentos, funcionalidades e normas orientativas para o uso ou aplicação eficaz do objeto em questão. São documentos elaborados com a finalidade de uniformizar os procedimentos a serem observados nas diversas áreas da atividade, sendo um ótimo instrumento de racionalização de métodos e aperfeiçoamento do sistema de comunicação, favorecendo a integração dos diversos subsistemas organizacionais, quando elaborados cuidadosamente com base na realidade da cultura organizacional [5]. Sua importância assegura a qualidade e a garantia dos itens mencionados, dando mais confiabilidade e melhor percepção, destacando como perdurar a durabilidade, satisfazendo assim suas possíveis dúvidas e trazendo novas expectativas em relação ao manual.

\section{II.3. ELEMENTOS NECESSÁRIOS PARA ELABORAÇÃO DE UM MANUAL}

O treinamento é um estudo comportamental, desempenha Para atender eficazmente seus usuários os manuais devem conter algumas exigências estabelecidas de acordo com o Manual de Organização do Management Center do Brasil diz que para facilitar seu entendimento precisa ter um formato cômodo que facilite seu manuseio e a sua guarda, seus tomos devem ser separados por um colecionador com as folhas soltas facilitando a consulta ou possível substituição, inclusão de índices geral e guias referentes aos títulos dos assuntos contribuindo para sua localização, tendo de uma linguagem clara e objetiva, mostrando o passo sequencial para execução dos procedimentos a serem almejados, bem como estudar o público destinado, sem causar desperdício na sua reprodução.

Portanto, a normalização deve prover à diminuição dos custos de variados produtos e procedimentos, buscando meios alternativos que permitam essa permuta de informações de ambas as partes seja do fabricante ou cliente, fidelizando as relações comerciais existentes, assegurando a qualidade de produtos ou serviços oferecidos aos consumidores.

\section{II.4. AS CONSEQUÊNCIAS DA INEFICIÊNCIA OU MAU USO DO MANUAL}

Sabe-se da importância de utilizar o manual, muitas vezes torna-se ineficiente devido à complexidade de sua linguagem técnica, dificultando sua compreensão, fazendo com que seus usuários deixem de consultá-lo prejudicando a execução de atividades, procedimentos, montagens e manutenção de produtos ou serviços, implicando em graves acidentes no manuseio incorreto por não lerem, ou em graves danos impactantes na organização. Embasado no [3] em relação às informações das responsabilidades de um produto ou serviço diz que é de total responsabilidade de seu fabricante, construtor, produtor seja nacional ou estrangeiro, pela reparação por danos causados aos seus consumidores em decorrência de defeitos, fabricação, montagens, fórmulas, manipulação deverão ser mencionadas ou readequadas para sua utilização e riscos. Essencialmente, para ser constatada a eficácia e a eficiência do uso de manuais necessitaria de um acompanhamento sucinto para atualização e aperfeiçoamento das informações disponibilizadas, proporcionando maior veracidade dos dados informados. 


\section{MATERIAIS E MÉTODOS}

O projeto de pesquisa de acordo com [6] é a sequência lógica que conecta os dados empíricos às questões de pesquisa iniciais do estudo e em última análise, às suas conclusões. Nesse intuito a metodologia recomendada foi a pesquisa exploratória de campo, pois conforme [7] ela é a atividade básica da ciência na sua indagação e construção da realidade, bem como, é a mesma que alimenta a atividade de ensino e a atualiza frente à realidade do mundo. Ou seja, para obter informações novas sobre um determinado assunto é preciso realizar a pesquisa. Assim segundo ele a metodologia ideal para análise de dados da pesquisa é trabalhar com a valorização das quantidades e da qualidade, com as contradições intrínsecas às ações e realizações humanas, do mesmo modo, com o movimento perene entre a parte e o todo e interioridade e exterioridade dos fenômenos.

Assim sendo, metodologia segue num primeiro momento com a revisão bibliográfica atualizada, onde foram utilizadas fontes primárias destacando-se o ponto de vista de vários autores em relação ao tema abordado. E em seguida foi realizada a aplicação de um questionário em campo, de natureza quantitativa e qualitativa contendo 6 (seis) perguntas do tipo múltipla escolha, ou seja, perguntas fechadas com quatro alternativas: nunca, raramente, ás vezes e sempre; vale salientar que as perguntas são sequenciais para confirmar e detectar a veracidade das informações. Finalmente 1 (uma) pergunta do tipo aberta para descobrir qual é a opinião e sugestão do entrevistado em relação aos manuais.

A técnica de abordagem foi direta, o questionário foi aplicado de forma que a distribuição deste utilizasse diversos grupos da população, com uma amostra intencional de 122 usuários de manual de ambos os sexos: feminino e masculino; buscando uma boa representatividade realizou-se, em parte, com indivíduos que possuem um grau de escolaridade a nível fundamental e médio com faixa etária variando entre 30 a 50 anos, e os demais entrevistados foram acadêmicos do ensino superior com idade de 20 a 40 anos.

Após a aplicação foi realizada a análise de dados. Então, o procedimento metodológico aplicado foi à utilização do questionário devido à praticidade e rapidez no fornecimento de subsídios para a pesquisa, abrangendo assim níveis de conhecimento distintos para descobrir o entendimento de cada um em relação ao assunto abordado.

\section{RESULTADOS E DISCUSSÕES IV.1. APLICAÇÃO DA PESQUISA}

Para que fosse possível obter resultados satisfatórios foram aplicados 122 questionários numa amostra escolhida de forma aleatória da população da cidade de Manaus que pudesse representar diversos públicos, tais como homens e mulheres, jovens e adultos, assim como, de variados níveis de escolaridade, permitindo que a pesquisa fosse mais fiel possível em relação à realidade a qual pretende se retratar.

Destarte, almeja-se oferecer embasamento necessário aos profissionais que se dedicam a criação e aprimoramento de manuais com aplicabilidades diversas, obtendo feedback de como ele é visto pelos usuários.

\section{IV.2. LEVANTAMENTOS DOS DADOS}

Foram escolhidas variáveis, as quais pudessem ser manipuladas na pesquisa no intuito de constatar e esclarecer a eficácia e eficiência no uso e aplicação de manuais com finalidades diversas tanto mercado, assim como, de procedimentos organizacionais, as quais foram representadas por seis (06) perguntas que compõe o questionário de forma objetiva, bem como, uma questão aberta para que fosse possível indicar sugestões. Seguem na sequência, os resultados obtidos pelo questionário aplicado.

A tabela 1 apresenta a resposta da pergunta "Você costuma ler o manual?" Onde apenas 15\% dos usuários informaram que sempre costumam fazer leitura dos manuais enquanto que $20 \%$ eventualmente e mais da metade dos usuários nunca ou raramente os leem. Na figura 1 temos resposta à pergunta "Considera os manuais de fácil entendimento?", mostrando, um percentual de $57 \%$ de usuários com dificuldade, apenas $2 \%$ tem facilidade de entendimento, enquanto que $41 \%$ são os que raramente ou às vezes tem facilidade de entendimento.

Tabela 1. Preferência de leitura.

\begin{tabular}{l|c|c}
\hline Alternativas & Percentual & Respostas \\
\hline 1. Nunca & $36 \%$ & 44 \\
\hline 2. Raramente & $30 \%$ & 36 \\
\hline 3. Às vezes & $20 \%$ & 24 \\
\hline 4. Sempre & $15 \%$ & 18 \\
\hline
\end{tabular}

Fonte: Autores, (2015).

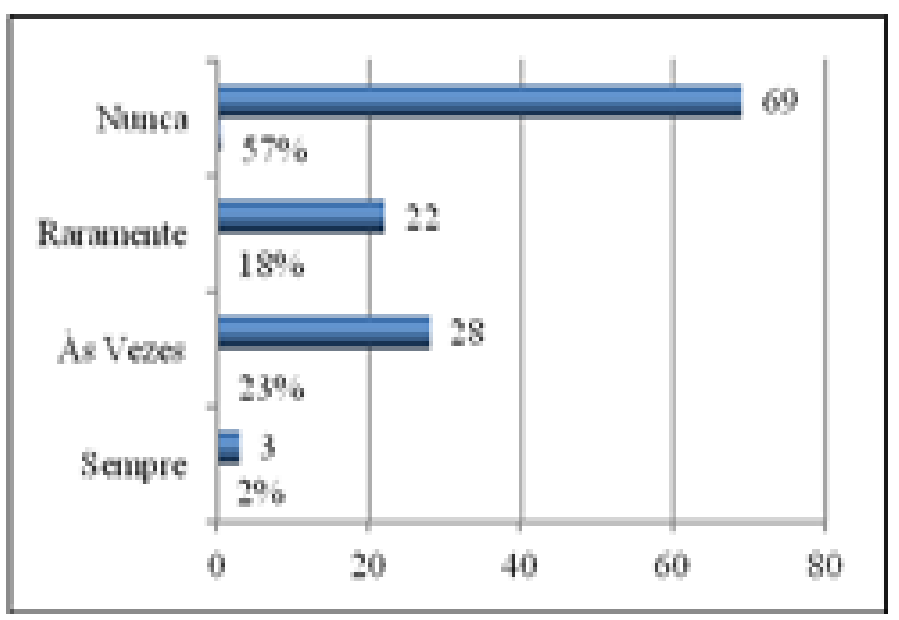

Figura 1. Facilidade de entendimento.

Fonte: Autores, (2015).

Os usuários ao serem perguntados "Com que frequência você costuma utilizar o manual?" 33\% responderam nunca como exibe a figura 2 , enquanto que, somente $6 \%$ informaram que sempre o utilizam, por outro lado $38 \%$ responderam raramente e $24 \%$ às vezes costumam utilizar.

A Tabela 2 apresenta como usuários responderam ao questionário que perguntava "Os seus manuais arquivados são de fácil acesso?", onde obteve $48 \%$ de respostas negativas, enquanto que apenas $9 \%$ informaram sempre os encontram facilmente, $29 \%$ informaram que raramente e outros $15 \%$ às vezes encontram manuais arquivados. 


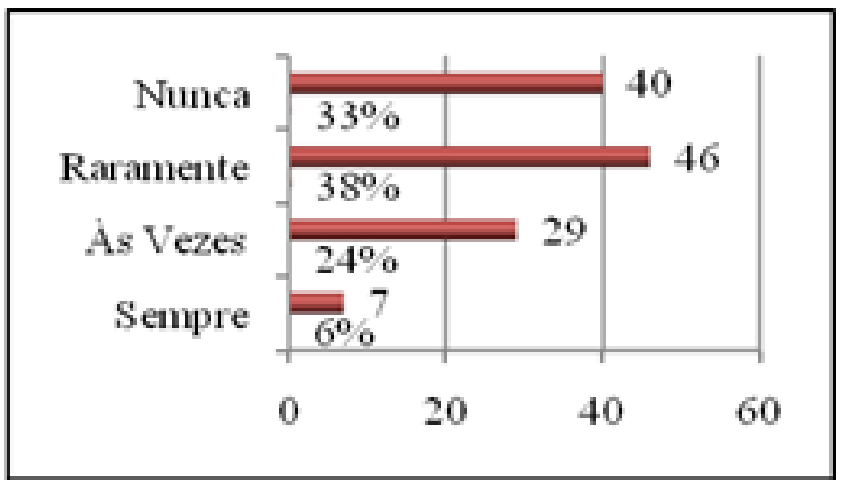

Figura 2. Frequência do uso.

Fonte: Autores, (2015).

Tabela 2. Facilidade de acesso ao manual.

\begin{tabular}{l|c|c}
\hline \multicolumn{1}{c|}{ Alternativas } & Percentual & Respostas \\
\hline 1. Nunca & $48 \%$ & 58 \\
\hline 2. Raramente & $29 \%$ & 35 \\
\hline 3. Às vezes & $15 \%$ & 18 \\
\hline 4. Sempre & $9 \%$ & 11 \\
\hline
\end{tabular}

Fonte: Autores, (2015).

Ao serem questionados sobre se o "Uso do manual é importante para as organizações?", conforme consta na tabela 3, umas parcelas de $66 \%$ dos usuários responderam ao questionário informando que sabem da importância do mesmo para as organizações, $23 \%$ acreditam que o mesmo às vezes, $7 \%$ raramente são importante e finalmente $4 \%$ entendem que os manuais não são importantes. A figura 3 exibe o posicionamento dos usuários ao serem perguntados "Em que momento você costuma consultar o manual?", onde apenas $8 \%$ deles responderam que antes de manusear costumam consultá-lo, $25 \%$ durante, $33 \%$ depois e $34 \%$ em nenhum momento consultam os manuais.

Tabela 3. A importância para as organizações.

\begin{tabular}{l|c|c}
\hline \multicolumn{1}{c|}{ Alternativas } & Percentual & Respostas \\
\hline 1. Nunca & $4 \%$ & 5 \\
\hline 2. Raramente & $7 \%$ & 9 \\
\hline 3. Às vezes & $23 \%$ & 28 \\
\hline 4. Sempre & $66 \%$ & 80 \\
\hline
\end{tabular}

Fonte: Autores, (2015).

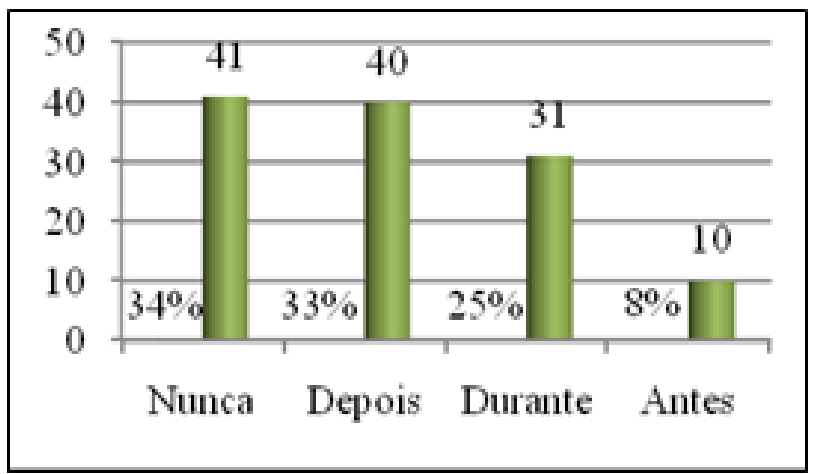

Figura 3. A consulta ao manual

Fonte: Autores, (2015).
Ao aplicar o questionário os usuários foram motivados a pensarem em sugestões de melhoria, as quais foram compactadas e classificadas em 10 categorias mais importantes e relevantes. Nesta pergunta não havia obrigatoriedade, assim, conforme mostra a figura 4, dos 122 indivíduos que responderam ao questionário, apenas 76 se prontificaram em dar sugestões de aprimoramento ou inovação do processo.

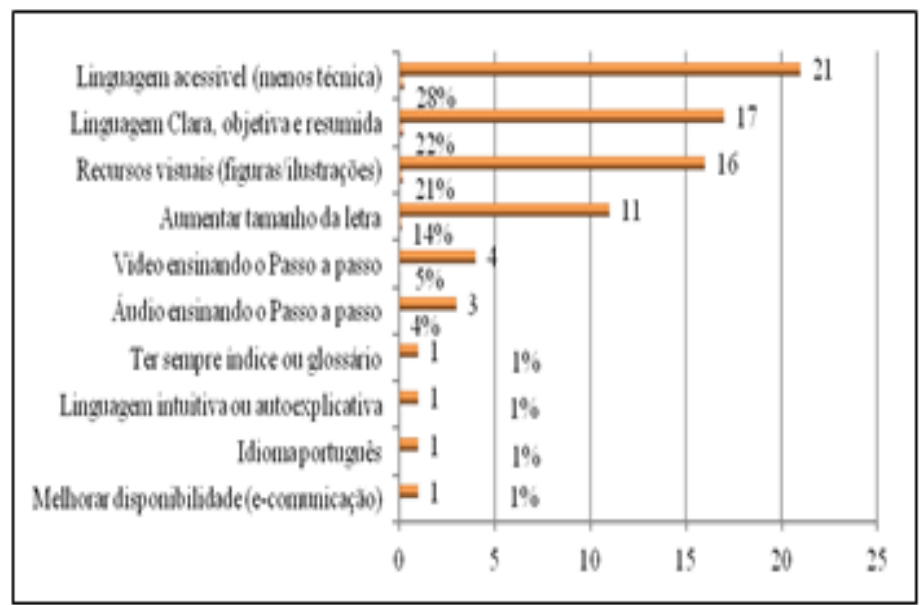

Figura 4. Sugestões dos usuários quanto à melhoria dos manuais Fonte: Autores, (2015).

No conjunto $28 \%$ sugeriram que a linguagem deveria ser mais acessível, ou seja, menos técnica, 22\% gostariam que a linguagem fosse mais clara, objetiva e resumida, $21 \%$ gostariam que houvesse mais recursos visuais e figuras, $14 \%$ mostraram insatisfação quanto ao tamanho da letra, $5 \%$ sugeriram elaboração de manual em formato de vídeo e outros $4 \%$ em áudio o restantes dos $4 \%$ foram subdivididas entre a obrigatoriedade do uso de índice, idioma português, linguagem intuitiva e autoexplicativa e disponibilidade do mesmo em meios de comunicação diversificado.

\section{IV.2 ANÁLISE E DISCUSSÃO DOS RESULTADOS DA PESQUISA}

Segundo afirma o Ministério Público Federal (MPF) no seu Relatório de Monitoramento da Implantação de Modernização da Gestão Administrativa [8] o manual deve ter uma redação simples, curta, eficiente, clara e inteligível. Portanto, é indispensável que o redator considere sempre a visão do leitor, procurando evitar linguagem rebuscada ou de difícil entendimento por aqueles que não dominam a linguagem técnica da área sobre a qual o manual instrui, ou seja, ele deve ser redigido partindo do pressuposto de que o leitor não conhece do assunto e que é o meio para ensiná-lo.

Ao avaliar os dados coletados conforme respostas ao questionário anteriormente exposto conforme consta na tabela 1 é claramente notável que existe uma evidente rejeição a leitura e uso dos manuais de forma geral, por parte dos usuários - como denominamos qualquer pessoa que tenha acesso a um novo produto, serviço e processo fabril ou laboral, representado por $36 \%$ dos usuários. Na mesma tabela, observa-se também, da fatia que complementaria $100 \%$ da amostra, ou seja, os $64 \%$ restantes, considerados "leitores de manuais", apenas umas parcelas ínfimas de $6 \%$ informaram usá-los de forma regular e constante, conforme figura 2 . 
Outro agravante que foi constatado é o fato de que, apenas $2 \%$ destes têm facilidade de compreensão ao lerem os manuais segundo figura 2 , ou seja, a grande parcela, em maior ou menos porção demonstra ter dificuldade em entender as informações e avisos constantes nos manuais, outro elemento a constar no questionário teve o objetivo de verificar como os manuais são guardados ou conservados, onde aproximadamente metade da amostra, ou seja, $48 \%$ dos usuários conforme tabela 2 relataram que estes não são arquivados ou bem armazenados de tal forma que se tornam inacessíveis quando necessários, portanto, conforme figura 3, os 33\% dos usuários que tem o hábito de consultá-lo após o primeiro momento, certamente são prejudicados. Nesta mesma tabela, é inteligível afirmar que a possibilidade da causa de $34 \%$ dos usuários nunca consultar o manual, seja também pelo fato do mesmo não ser encontrado quando necessário.

Todos estes agravantes, demonstram a importância da necessidade de um estudo mais profundo a respeito deste assunto, uma vez que é imprescindível advertir o fato de que a não utilização ou mau uso dos mesmos, poderiam acarretar um grave perigo ou problema de um lado para os próprios usuários e por outro lado, às organizações que ao implementá-lo tem como objetivo levar informações de grande importância que precisam ser apreendidos pelos usuários. Conforme estabelece a legislação no seu código de defesa do consumidor através da lei 8.078/90, no seu artigo 31 que diz, "a oferta e apresentação dos produtos ou serviços devem assegurar informações corretas, claras, precisas, ostensivas e em língua portuguesa sobre suas características, qualidades, quantidade, composição, preço, garantia, prazos de validade e origem, entre outros dados, bem como sobre os riscos que apresentam à saúde e segurança dos consumidores", sobre pena de incorrerem sanções econômicas, prejuízos materiais e imateriais como perca da confiança de seus fiéis clientes e colaboradores que constituem os bens mais nobres e preciosos de qualquer organização [3].

\section{IV.3. RELEVÂNCIA DA INOVAÇÃO E/OU APRIMORAMENTO DOS MANUAIS}

O tema escolhido leva em consideração as suposições e conjecturas as quais foram confirmadas pelo resultado obtido através da aplicação dos questionários, visando à importância dos manuais e no intuito de propiciar aos colaboradores e clientes sejam internos ou externos, retornos mais eficazes, eficientes, práticos e acessíveis e levando em consideração a necessidade de cada usuário conforme figura 4 , obtiveram-se recomendações que demonstram as deficiências oriundas da lacuna existente entre a situação real e ideal. Assim, foi percebido que, houve sugestões quanto a melhoria dos manuais, nos moldes atuais tais como: aprimoramento da linguagem, tornando-o mais acessível e menos técnica, sendo clara, objetiva e compacta, com emprego de recursos visuais, tais como figuras e ilustrações que o tornam intuitiva e autoexplicativa.

No entanto, considerando que o manual é um instrumento importante que no atual cenário macroeconômico onde é necessário acompanhar a celeridade das mudanças e numa conjuntura de modernização é primordial conforme sugere o [8] manual deva primar à flexibilidade e adaptação diante das futuras realidades, podendo sofrer modificação e revisões normalmente requeridas pela necessidade de melhoria contínua dos serviços prestados.
Destarte segundo a figura 4 , houve propostas inovadoras as quais permitem visualizar novas alternativas com maior leque de possibilidades, tais como, implementação de manuais em formato de áudio e vídeo, que podem estar disponíveis em qualquer momento nos meios modernos e "ininterruptos e disponíveis" de comunicação tais como internet que segundo [9] a comunicação eletrônica é uma troca de dados ou informações de qualquer natureza entre duas ou mais partes em que a transmissão depende da lei do eletromagnetismo e que comunicação eletrônica é hoje onipresente, insubstituível e poderoso, assim, deve ser considerado um recurso indispensável para todas as organizações com devidas ressalvas quanto às políticas de segurança que o meio eletrônico assim como qualquer outro meio exige. Tais manuais também podem ser conhecidos como ferramentas on-line de compartilhamento ou e-manuais.

Deste modo, no intuito de, atender a satisfação dos clientes e permitir constante atualização, uma vez que de acordo com [10] manuais técnicos em suporte de papel podem ser substituídos por sistemas eletrônicos, que incorporaram elementos de multimídia e hipermídia para fornecer suporte just-in-time para o usuário durante a vida de um produto, evoluindo assim para sistemas de suporte interativo de produtos baseados na plataforma $W W W$ que possibilitam a disseminação, de modo democrático, completo e complexo, abarcando módulos integrados de especialização em diagnóstico e solução de problemas, atendendo e evoluindo de forma adequada de acordo com as necessidades dos usuários.

É indispensável que tal ferramenta seja concretizada por especialistas obedecendo cada estágio de desenvolvimento do produto que tem como início a especificação de requisitos, coleta e estruturação de dados de produtos, o desenvolvimento da base de conhecimento, criação, verificação, avaliação, publicação e manutenção.

Embasados nos requisitos do usuário e a engenharia do conhecimento, levando em consideração a importância e primazia da interação homem-computador que vem ascendendo a cada dia na sociedade hodierna, sem dar a devida atenção à evolução e a integração das informações sobre os produtos e os mecanismos de apoio just-in-time relevantes para proporcionar a disponibilidade dos manuais quando são necessários.

Para se obter resultados aceitáveis e apropriados deve então, obrigatoriamente determinar, unificar e padronizar metodologia específica para a concepção de manuais e posteriormente segui-los de forma sistemática e rigorosa, padrão esta que serve de base fundamental e uniforme, ou seja, pilares sob os quais qualquer tipo de manual pode e deve ser inicialmente construído.

Assim, conforme [11] todo o trabalho que trouxer riscos operacionais, riscos ao meio ambiente e de segurança deve ser padronizado. Por outro lado, estas atividades consideradas críticas e deste modo, padronizadas se formatadas, distribuídas e utilizadas eletronicamente, além disso, contribuem positivamente com o fator ecológico-ambiental, agregando valor ao produto uma vez que, evita o uso de matéria prima e produção de resíduos a partir de confecção e descarte de manuais em papel, deste modo, de um lado torna um elemento diferencial em termo de marketing verde que além de proporcionar satisfação, confiança e fidelização dos clientes, por outro lado propicia economia, minimização de desperdício e em última análise e não menos importante ganhos econômicos a organização. 
Do mesmo modo e não menos importante, os e-manuais tem como vantagens, proporcionar aos usuários praticidade, comodidade, economia de tempo, eficácia e eficiência, em tempo que ao meio acadêmico abrem um vasto campo promissor, que promovem oportunidades inúmeras de novas pesquisas e estudos, aprofundando-se mais ao que se refere o tema.

\section{CONCLUSÕES}

A presente pesquisa proporcionou um melhor entendimento quanto à utilização dos manuais e sua aplicabilidade, sejam referentes a um produto, procedimento ou serviço. O manual tem por escopo orientar e elucidar as dúvidas dos usuários, a respeito das funcionalidades dos equipamentos, processos de atividades laborais, assim como visão, missão, perspectivas ou descrição de cargos ao se tratar de um manual organizacional.

Percebe-se que os manuais da forma que são confeccionados não atendem as necessidades dos usuários, não há um esclarecimento correto e satisfatório quanto ao uso devido dos manuais e isso pode ocasionar perdas e oferecer contratempo aos usuários e dependendo do produto, até mesmo risco ou perigo de vida. Por fim, recomenda-se que sejam posteriormente levados em conta os resultados que esta pesquisa aponta e considerar analise e reflexão a respeitos das seguintes propostas e observações: que os manuais agreguem ilustrações precisas que os tornem eficaz e eficiente, ou seja, mais imagens de passo a passo ao invés de texto ininterruptos, que o texto seja claro e objetivo e que tenha um tamanho de fonte maior e uma escrita e vocabulário menos técnico, tornando-o acessível ao entendimento do público diversificado.

Com o avanço da tecnologia sugere-se também que as empresas criem manuais eletrônicos com vídeos e áudios autoexplicativos, disponíveis em CD, DVD, na internet, sites exclusivos da empresa e de seus parceiros comerciais, para assim satisfazer melhor e atender as necessidades do usuário final.

\section{AGRADECIMENTOS}

Ao Centro Universitário do Norte (UNINORTE) pelo apoio a realização desta pesquisa.

\section{REFERÊNCIAS}

[1].PIMENTA, Maria Alzira. Comunicação Empresarial: conceitos e técnicas para administradores. 7. ed. São Paulo: Editora Alínea, 2010.

[2].VARGAS, Graziela Mônaco. Estudos básicos sobre normalização: origem, conceitos e organismos reguladores. Rio Grande do Sul: 2006. Disponível em: <http://rabci.org/rabci/sites/default/files/Trabalho_FINAL_ Normalizacao.pdf> Acessado em: 28/04/2014.

[3].Código de Defesa do Consumidor - Nova Ed. Ver, atual e ampl. Com o Decreto n 2.181, de março de 1997 - Brasília: Ministério da Justiça, 2001.

[4].MELO, Vanessa Pontes Chaves de. A comunicação interna e sua importância nas organizações. São Paulo: 2009. Disponível em: <http://www.acmcomunicacao.com.br/wp-content/midias/Acomunicacao-interna-e-sua-importancia-nas-organizacoes-

Vanessa-Pontes-Chaves-de-Melo.pdf> Acessado em: 15/04/2014.
[5].CURY, Antonio. Organização e métodos: uma visão holística. São Paulo: Atlas, 2007.

[6]. YIN, Robert K. Estudo de caso: planejamento e métodos. 4. ed. Porto Alegre: Bookman, 2010.

[7].MINAYO, Maria Cecília de Souza (org.). Pesquisa Social: teoria, método e criatividade. 26 ed. Petrópolis: Vozes, 2007.

[8].MINISTÉRIO PÚBLICO FEDERAL - MPF. Modelo para elaboração de manual de normas e procedimentos dos processos organizacionais do MPF. Rio de Janeiro: 2011. Disponível em: <http://www.modernizacao.mpf.mp.br/copy_of_relatorios/> Acessado em: 27/04/2014.

[9].TURKANOVIĆ, Muhamed; POLANCIC, Gregor. On the security of certain e-communication. Journal of Information Security and Applications Volume 18, Issue 4, December 2013, Pages 193-205

[10].SETCHI, R.M, PHAM, D.T, DIMOV, S.S. A methodology for the development of intelligent products manuals. Engineering Applications of Artificial Intelligence, Volume 19, Issue 6, September 2006, Pages 657-669.

[11].ANTÔNIO, Qualidade \& Gestão 2012: padronização, 2012. Disponível em: <http://blog. qualidadesimples.com.br/2012/05/30/qualidade-gestao-2012-22/> acessado em: 15/04/2014. 